\title{
Differential mentorship for medical students: development, implementation and initial evaluation
}

\author{
Jennifer Kurré1, Monika Bullinger ${ }^{1}$, Corinna Petersen-Ewert ${ }^{2}$, Andreas H. Guse ${ }^{3}$ \\ ${ }^{1}$ Department of Medical Psychology, University Medical Center Hamburg-Eppendorf, Germany \\ ${ }^{2}$ Faculty of Economy and Social Affairs, Hamburg University of Applied Sciences, Germany \\ ${ }^{3}$ Dean's Office of Education and Students' Affairs, University Medical Center Hamburg-Eppendorf, Germany
}

Correspondence: Andreas H. Guse, Department of Biochemistry and Molecular Cell Biology, University Medical Center Hamburg-Eppendorf, Martinistrasse 52, 20246 Hamburg, Germany. Email: guse@uke.de

\begin{abstract}
Objectives: The aim of this study was to develop a uniquely tailored mentoring program for medical students and evaluate the success of implementation.

Methods: A cross-sectional survey among medical students at University Medical Center Hamburg-Eppendorf, Germany, in 2007 (response rate 74\%, n=1235) was administered to explore student needs for an individual counseling service (mentoring program). These data were supplemented with additional qualitative data (telephone interviews $(n=52)$ and expert panels). The success of implementation was evaluated according to publicity and participation within the target group.
\end{abstract}

Results: In total, $66 \%(n=798)$ of the students claimed an interest in a mentoring program. With regard to possible challenges related to the launching of a new program, awareness was frequently mentioned. Experts suggested the establishment of a differential mentoring program consisting of three parts that is tailored to students' individual performance. Thus, a mentoring program providing individual and voluntary mentoring for all medical students was designed. The program attracted $40 \%(\mathrm{n}=104)$ of medical students when it was launched in 2009. Participation increased continuously in 2010 (cohort 2009: 49\%, $\mathrm{n}=150$ ) and 2011 (cohort 2010: 51\%, n=126).

Conclusions: The initial needs analysis followed by a serious decision-making process within the faculty was identified as an important predictor for the successful establishment of an innovative mentoring program at a large faculty. Differential mentorship may assist medical schools in ensuring both equal opportunities and the promotion of diverse talent.

Keywords: Mentoring, medical education, counseling, medical students

\section{Introduction}

Mentoring in academic medicine has been applied in many different ways to support both students and young physicians. According to Sweeney, "Mentoring is a partnership between two people built upon trust. It is a process in which the mentor offers ongoing support and development opportunities to the mentee. Addressing issues and blockages identified by the mentee, the mentor offers guidance, counseling and support in the form of pragmatic and objective assistance. Both share a common purpose of developing a strong two-way learning relationship". ${ }^{1}$ Moreover, Clutterbuck defined mentoring as a fifth dimension that encompasses coaching, networking, guiding, and counseling. ${ }^{1}$ He describes coaching as a relatively directive means of assisting an individual in developing competences, whereas counseling is defined as a relatively non-directive means in the context of support and learning. The current literature provides no clear distinction among the terms counseling, tutoring or mentoring for medical students, and programs vary in their official names and structures. ${ }^{2,3}$

Mentoring in academic medicine spans a remarkably wide range of applications. ${ }^{2,4,5}$ Examples include fostering professional development for female academics ${ }^{6-8}$, improving medical school performance in general or focusing on minority medical students ${ }^{9-12}$, mentoring as a part of other 
interventions (e.g., in-depth learning), reflection in the context of portfolio use ${ }^{13,14}$, and increased interest in research. ${ }^{15,16}$ Thus, mentoring programs may be considered structures that broadly foster life-long learning and are regarded as predictors of success in both the study and lifelong education and training of physicians. In contrast with these positive effects and the importance of mentoring, several recently published studies reveal a striking lack of mentoring in academic medicine in Europe. ${ }^{17-19}$ Several studies have suggested that entering medical school is perceived as particularly stressful. ${ }^{20,21}$ Furthermore, undergraduate medical training may lead to severe psychological distress $^{22}$; for example, a lack of perceived interpersonal support increases the risk for depression more than tenfold. ${ }^{23}$

Together, these findings led us to conduct a crosssectional survey at the University Medical Center Hamburg-Eppendorf (UMC) to assess the situation of undergraduate students at a large medical school in Germany (with an annual intake of approximately 380 students). In addition to curriculum-related issues, interest and motivation, student well-being, and general self-efficacy beliefs, we sought to examine the need for a new counseling service. As a result, the majority of students expressed a great need for a counseling program.

The curriculum at medical schools in Germany encompasses 6 years and 3 months and is divided into two parts: the pre-clinical (undergraduate) part (2 years) primarily covers basic science, whereas the second part (4 years) encompasses clinical science and a final clinical year to learn skills on the job. ${ }^{24}$ Most medical schools in Germany do not require tuition fees despite the high costs of medical studies (more than 180,000 Euros per student). ${ }^{24}$ Because of the need for well-trained physicians, there is great public interest in selecting the best applicants and further supporting their personal and professional development to the highest degree.

To offer optimal support to medical students at an early stage, we used the survey results and data that were obtained from a pilot trial at the $\mathrm{UMC}^{25}$ for the following purposes: (i) to design a mentoring program that is suitable for a large-scale medical school and that precisely meets the demands of both students and faculty, (ii) to implement such a program using an approach based on the Shewhart cycle $^{26}$ with four steps: Plan-Do-Check-Act (PDCA) to continuously monitor program action, and (iii) to formatively evaluate and optimize the program by referring to the iterative view of design and evaluation of complex interventions in general. ${ }^{27}$

The literature reveals a high discrepancy between reported counseling needs and the actual use of counseling services. $^{28,29}$ A lack of information about and accessibility of counseling services that are located far away from a medical campus and stigmatization are discussed as potential barriers to accessing counseling. ${ }^{30,31}$ Therefore, key criteria for successful implementation are publicity and acceptance within the target group. Especially for medical schools with large numbers of students, the successful implementation of a mentoring program for students represents a challenge. ${ }^{32}$ The principal objectives of this article are to describe the development and implementation of a differential mentoring program for medical students. Differential mentoring is defined as a formal mentoring program consisting of three parts: Basic Mentoring Program for all students, Mentoring Program PLUS for students with low performance and Mentoring Program for Excellent Students. Furthermore, an initial evaluation is conducted to monitor the success of implementation.

\section{Methods}

We chose a mixed-methods approach consisting of a crosssectional survey and telephone interviews in 2007, two expert panels in 2008 and 2009, and annual course evaluations (online surveys) in 2009, 2010 and 2011. The methods will be described below.

The ethics committee of the Medical Chamber of the state of Hamburg was involved, but this study did not require approval from the ethics committee for the following reasons. Students' participation was voluntary and anonymous. Further, it was not possible to identify participants via the data they contributed. Students were asked to complete the questionnaire (paper format) subsequent to compulsory courses if they were interested. According to ethical guidelines the authors (JK and CPE) explained the purpose of the study and assured that there would not be any disadvantage for non-participating individuals. Furthermore we assured the confidentiality and anonymity of any contributed data. The survey was distributed together with a written information sheet and participants had the opportunity to ask questions. Completed questionnaires were collected one week later by one of the authors (JK) in a closed box. Students who were interested in participating in the telephone interviews returned their contact data and written informed consent on two additional forms, which were stored separately in locked containers.

\section{Survey among undergraduate medical students}

The survey was designed as a cross-sectional study including all students in the pre-clinical part. The data were collected on the basis of academic terms: $2^{\text {nd }}$ and $4^{\text {th }}$ semester students were asked to participate in May 2007, students in their $1^{\text {st }}$ and $3^{\text {rd }}$ semesters were asked to participate in November 2007. In the context of this survey, the authors sought to assess student attitudes toward and needs for a new counseling service. To identify important topics that concern medical students, the investigators developed 18 items that seek to determine the importance of each topic. Ten items were designed to assess student mentoring needs and the preferred form. With seven items, the authors sought to explore important information pathways for a 
new mentoring program. Rather than "mentor"/"mentoring" or "tutor"/"tutoring," the investigators used the global term of "counseling service" to avoid any bias because it was unclear which approach would optimally meet the needs of students at a large medical school. All items use a four-point Likert scale ranging from 1=disagree to $4=$ agree. For the data analysis, we describe the importance of the topics using counts and percentages. The need for and the setting of mentoring were analyzed as dichotomous variables $(1-2=$ overall negative; $3-4=$ overall positive).

\section{Telephone interviews}

Furthermore, the authors conducted semi-structured telephone interviews to gain more detailed information regarding student mentoring needs. Out of 149 undergraduate students who participated in the cross-sectional survey described above and volunteered to participate in an additional telephone survey, we selected a random sample of 52 students. The participants were informed of the purpose of the interview and assured of the confidentiality and anonymity of any contributed data. All data were stored anonymously and electronically in compliance with data protection regulations in Germany. At the beginning of the interview, the participants were asked whether they are personally interested in using a new counseling service. Subsequently, they were asked to describe their experience with the existing counseling services and possible improvements for a new service. The final question focused on the preferred topics of the participants. The authors employed a conventional content analysis. ${ }^{33,34}$ Data reading was followed by coding sheet development and stepwise inductive category development. Subsequently, the data were recoded by two of the authors (JK and CPE) using the same coding sheet. Different views of the (sub) categories were discussed to establish a consensus.

\section{Expert panels on the mentoring program}

The successful establishment of a formalized mentoring program requires acceptance and commitment within the faculty. Clutterbuck ${ }^{1}$ suggested the consideration of several aspects: first, to understand how the culture of the medical school will support or hinder mentoring; second, to ensure commitment of several stakeholders (top management in terms of the faculty board and medical directors, mentors, and mentees); and third, to adapt the mentoring program to the environment of a large-scale medical school. For a concerted approach, the deanery invited experts in medical education (expert panel 1: directors of the student advice and psychological counseling service of the University of Hamburg, experienced pre-clinical and clinical teaching staff at the medical school; expert panel 2: as specified previously, in addition to mentors and mentees (students) participating in the mentoring pilot trial) for an initial workshop in February 2008 and a follow-up meeting in 2009. The objective was to discuss key domains of mentor218 ing derived from the literature $e^{5,28,35-38}$ and web research and to identify key aspects of a differential mentoring program. Eleven people (expert panel 1) and eight people (expert panel 2) participated in the 2-hour workshops. The agenda began with a presentation of empirical data (based on the literature and the benchmarking of mentoring programs at German medical schools). Subsequently, the key domains of a prospective mentoring program were discussed, including structure, objectives, mentor recruitment, the matching process and quality management.

\section{Evaluation of implementation}

The key criteria for the successful implementation of a new counseling service are publicity and acceptance within the target group. Therefore, after the implementation of the differential mentoring program in 2009, the authors surveyed all students at the end of their first year regarding their awareness of and participation in the program. In the context of regular (web-based) course evaluations, which are conducted twice per year by the deanery, the authors applied two items with dichotomous answer categories (yes/no): "Do you know the mentoring program for students?" and "Do you participate in the mentoring program for students?" The data are described using counts and percentages.

\section{Results}

\section{Survey among undergraduate medical students}

The respondents were students from four semesters ( $\mathrm{n}=335,237,347$, and 316 for semesters 1 through 4, respectively), with an overall response rate of $74 \%$. Approximately $66 \%(n=798)$ of the students claimed an interest in a new type of individual counseling service. Between the $1^{\text {st }}$ and $4^{\text {th }}$ semesters, the interest in this new type of service decreased. However, except for the $1^{\text {st }}$ semester students, who primarily preferred more advanced students as counselors, there was a marked request for experienced members of the faculty to serve in this new type of structured counseling system. The majority of the students favored staff members of the UMC as prospective counselors, either staff members that they know from courses $(n=614 ; 51.3 \%)$ or professional counselors $(n=877$; $73.1 \%$ ). A web-based system was preferred by only $19 \%$ to $23 \%$ of students (Table 1 ).

Figure 1 displays the six most frequently mentioned topics that were rated as "important" for a new counseling service. The students considered career-related objectives (studying and working abroad $(\mathrm{n}=554,45.4 \%)$, scientific work $(n=308,25.4 \%)$ and career counseling $(n=298,24.4 \%))$ and psychosocial issues (coping with stress $(n=419,34.3 \%)$, exam nerves $(n=405,33.2 \%)$ and learning strategies $(n=389$, $31.9 \%)$ ) as the most important areas of concern.

Asked about the importance of information pathways to introduce a new counseling service at the UMC, the participants considered an eLearning platform for students and 
Table 1. Student needs for a new counseling service (mentoring program) and attitudes toward different settings displayed as overall positive (cross-sectional survey, $n=1235$ )

\begin{tabular}{|c|c|c|c|c|c|}
\hline \multirow{2}{*}{ Item } & $\begin{array}{l}1^{\text {st }} \text { Semester } \\
\quad(n=335)\end{array}$ & $\begin{array}{l}2^{\text {nd }} \text { Semester } \\
\quad(n=237)\end{array}$ & $\begin{array}{l}3^{\text {rd }} \text { Semester } \\
\quad(n=347)\end{array}$ & $\begin{array}{l}4^{\text {th }} \text { Semester } \\
\quad(n=316)\end{array}$ & $\begin{array}{c}\text { Total } \\
(\mathrm{n}=1235)\end{array}$ \\
\hline & $\mathrm{n}(\%)$ & $n(\%)$ & $n(\%)$ & $n(\%)$ & $\mathrm{n}(\%)$ \\
\hline I would use the new counseling service. & $263(79)$ & $138(62)$ & $222(65)$ & $175(57)$ & $798(66)$ \\
\hline $\begin{array}{l}\text { I think I could solve a possible problem with the assistance of a } \\
\text { counselor. }\end{array}$ & $272(81)$ & $158(71)$ & $244(71)$ & $204(66)$ & $878(73)$ \\
\hline I would know how to contact a counselor. & $222(67)$ & $143(64)$ & $196(58)$ & $199(65)$ & $760(63)$ \\
\hline I would be worried about confidentiality. & $79(24)$ & $57(26)$ & $74(22)$ & $92(30)$ & $302(25)$ \\
\hline $\begin{array}{l}\text { I would prefer trained students from higher semesters as } \\
\text { counselors. }\end{array}$ & $181(55)$ & $93(43)$ & $112(33)$ & $113(37)$ & $499(42)$ \\
\hline $\begin{array}{l}\text { I would prefer professional counselors who are employed at the } \\
\text { UMC. }\end{array}$ & $218(66)$ & $155(71)$ & $273(80)$ & $231(75)$ & $877(73)$ \\
\hline $\begin{array}{l}\text { I would prefer staff whom I had met personally in courses as } \\
\text { counselors. }\end{array}$ & $144(44)$ & $126(58)$ & $175(51)$ & $169(55)$ & $614(51)$ \\
\hline I would prefer external professionals as counselors. & $147(44)$ & $79(36)$ & $139(41)$ & $120(39)$ & $485(40)$ \\
\hline I would prefer a web-based counseling service. & - & $44(20)$ & - & $78(23)$ & $122(23)$ \\
\hline I would prefer an anonymous, web-based counseling service. & - & $43(20)$ & - & $68(22)$ & $111(21)$ \\
\hline
\end{tabular}

*All items were rated on a four-point Likert scale that ranged from 1=disagree to $4=$ agree. The answers were dichotomized (1-2=overall negative; 3-4=overall positive) and shown in absolute numbers $(n)$ and percentages $(\%)$

staff to be the most important ( $\mathrm{n}=531,61.2 \%)$, followed by the UMC website $(n=468,53.9 \%)$ and informational events before or after main lectures ( $n=431,49.8 \%)$.

\section{Telephone interviews}

In a telephone survey that included 52 undergraduate students, $65 \%(n=34)$ of the students expressed a personal interest in a future individual counseling program at the medical faculty. Asked about their experience with existing counseling services, the participants criticized their availability (opening hours and location), publicity and lack of understanding of the (learning) environment of medical students with little spare time and demanding workloads. With regard to possible improvements that could be incorporated into a future counseling service, the participants mentioned individual on-site counseling that is flexible with regard to appointments and topics. Furthermore, the desire for the proper advertising of any new services was reported. Classifying the responses with regard to the preferred topics of this program, we found that three topics were mentioned most frequently: "support regarding studying abroad", "support regarding the organization of studies" and "psychological counseling".

\section{Expert panels on the mentoring program}

Members of the expert panels agreed on the following general aspects and differential structure of the mentoring program.

General aspects: The members of the expert panels scheduled the launch of the mentoring program for the summer term of 2009 for all $2^{\text {nd }}$ semester students and chose to implement a gradual expansion to include the subsequent cohorts at the time that they enter their $2^{\text {nd }}$ semester. Mentoring should be provided for the preclinical period ( $2^{\text {nd }}$ through $4^{\text {th }}$ semesters) with the option for a smooth transition to clinical curriculum ( $5^{\text {th }}$ through $12^{\text {th }}$ semesters). The frequency of meetings should be based on the demands of students and the resources of mentors. Furthermore, the participants suggested compensation for mentoring meetings (beverage and food) by the faculty. To disseminate information regarding the new service, the participants recommended a mentoring website to be launched via intranet and administered by the deanery. Further suggestions include the introduction of the new program via several informational events for students and faculty and the establishment of seminars for all mentees to address desired topics, such as "how to apply for scholarship funds".

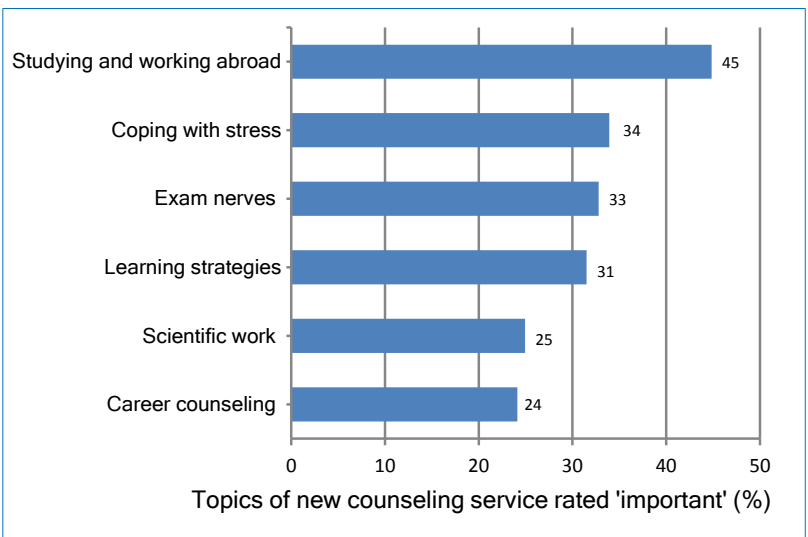

Figure 1. Topics for a new counseling service rated as "important" (cross-sectional survey, $n=1235$ )

*All items were rated on a four-point Likert scale that ranged from $1=$ not important to $4=$ =important 


\section{Criteria for selecting mentors}

As general criteria for selecting mentors, the participants recommended that mentors have a minimum of two years of professional experience at the UMC to ensure their ability to socialize mentees with respect to the norms and values of the UMC. Furthermore, mentors should display substantial interest in the supervision of students and attend an initial 2-hour training course.

\section{Matching mentees and mentors}

The members of the expert panels strongly recommended that students should choose their mentors. Initially, the matching process was suggested to be based on mentor profiles presented on the intranet. The profiles should include information regarding each mentor's area of interest, career-related aspects, hobbies and, most importantly, the mentor's expectations regarding prospective mentees and his mentorship proposal to students.

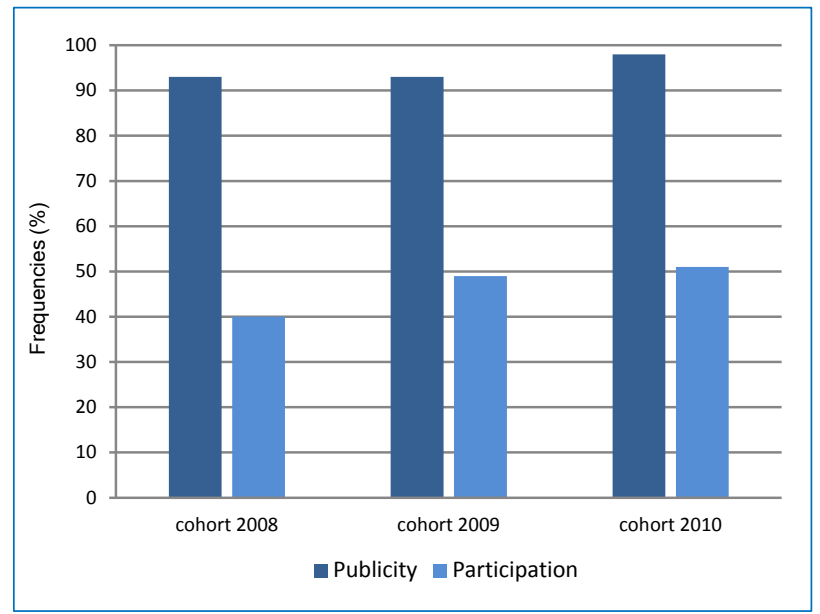

Figure 2. Self-reported publicity for differential mentoring program and participation of cohorts $2008 \quad(n=296), 2009$ $(n=304)$ and $2010(n=248)$

\section{Quality management}

To monitor the process of implementation and the continuous mentorship process, the members of the expert panels recommended an annual evaluation by mentees and mentors. For the assessment of the quality of the results, the following criteria were defined: (i) the publicity and acceptance of the mentoring program as judged by students, (ii) the satisfaction of mentees and mentors, (iii) the increased attractiveness of the medical school, (iv) enhanced communication between students and faculty, (vi) the increased success of students with study problems (Mentoring Program PLUS), and (vii) increased research motivation among students (Mentoring Program for Excellent Students).

Differential structure and objectives: depending on the purpose and setting, mentoring can take several forms. The experts recommended that mentoring for all students (named the "Basic Mentoring Program") and mentoring for students with low or high performance should be organized 220 separately (named "Mentoring Program PLUS" and "Mentoring Program for Excellent Students"). Thus, the three parts are distinguished by their aims, the mentoring model (group mentoring versus 1:1 mentoring) and the background of mentors.

\section{Basic mentoring program}

For the Basic Mentoring Program, the members of the expert panels recommended group mentoring involving eight mentees and one mentor as well as one-on-one settings when necessary. Mentors should be recruited from various departments of the medical school to ensure that they meet the specific interest of multiple mentees.

According to the members of the expert panels, the specific aims of the Basic Mentoring Program should encompass the following: (i) the provision of personal guidance and counseling for all students by mentors, (ii) the establishment of a personal network between students and faculty members and (iii) enhanced communication between students and faculty. Matching is based on the webbased profiles of mentors as described above. Similarly, students should apply for mentoring using a web-based application form containing contact data, a ranking list of three mentors that they prefer, the goals that they wish to attain through the support of a mentor and their expectations regarding the mentoring group. According to the preferences of students and the capacity of mentors, mentoring groups should be formed by the project coordinators, and mentors should be provided with contact data to enable them to invite prospective mentees. Following the first faceto-face meeting, both parties (mentees and mentors) should provide feedback as to whether the matching was successful. If the matching fails, then students could be re-matched with other preferred mentors.

\section{Mentoring program PLUS}

Suggestions for the Mentoring Program PLUS include oneon-one mentoring. Mentors must be from the area of psychosocial research or possess professional expertise in counseling. Because the Mentoring Program PLUS is intended to support students with low performance, its additional aims are the following: (i) to balance study demands and individual capabilities and skills, (ii) to implement and continue a low-threshold mentoring program for students with specific requirements (e.g., language problems, chronic diseases, or disabled students), and (iii) to increase the success rate at which students pass the first part of the German Medical Examination within the required period of 2 years. Matching should be conducted as a two-stage procedure. Experts proposed that these students should be invited to an inaugural event to introduce the Mentoring Program PLUS and engaged mentors who are known by their web-based profiles. Mentors should briefly introduce themselves, and an offer to meet at the buffet should follow. Subsequently, students should use the application form that is described above. 


\section{Mentoring program for excellent students}

First, the experts stated that students must qualify for the program based on excellent performance and a high interest in a career as physician-scientist. Similarly, mentors should be derived from a group of experienced faculty researchers. The minimum qualification for these mentors is a doctorate degree in either medicine or science. Furthermore, such mentors must be a member of an established research center at the UMC (e.g., the Hamburg Center of NeuroScience). For the "Mentoring Program for Excellent Students," the experts decided on group mentoring involving four mentees and one mentor. As main objectives, the experts recommended introducing students to research, promoting academic careers and supporting personal and professional development by creating opportunities for students to participate in research projects. More specifically, the experts recommended the introduction of mentees to the mentor's field of research and the organization of an annual retreat for all mentees and mentors to foster networking.

Matching should proceed via two steps. First, students choose one of five established research centers at the UMC based on web-based information and mentor profiles. Second, students and mentors are invited to an inaugural event to introduce the Mentoring Program for Excellent Students and attend a speed-mentoring session with the subsequent choice of mentor or mentees, respectively.

\section{Evaluation data regarding publicity and participation}

Because the items that measure publicity and participation have been addressed in the context of the well-established course evaluations, the response rates are satisfying (cohort $2008 \mathrm{n}=296$ (87\%), cohort $2009 \mathrm{n}=304$ (93\%), and cohort $2010 \mathrm{n}=248(60 \%))$. Figure 2 shows that the differential mentoring program is well known within the target group. The vast majority of the students (93\% (cohort 2008, cohort 2009) to $98 \%$ (cohort 2010)) reported that they are aware of the new program. Furthermore, participation is increasing constantly. When the mentoring program was initially launched, $40 \% \quad(n=117)$ of the cohort (2008) reported participating in the program. Only one year later, $49 \%$ of the students (cohort $2009 \mathrm{n}=150$ ) reported their participation, followed by 51\% of participants in 2011 (cohort 2010 $\mathrm{n}=126)$.

\section{Discussion}

In this report, we describe the development, implementation and initial evaluation of a new differential mentoring program for medical students. Consistent with previous research, our results indicate a high need for formal mentoring (Table 1). 2,19,32 Clearly, such an approach is labor- and cost-intensive for a large medical school in terms of the administration of the mentoring process (e.g., information for students, the training of mentors, and the matching of mentees and mentors). Evaluation and optimization needs require an additional small administrative unit. Further- more, mentors must spend time with their mentees; because mentors are members of the groups of professors, clinical senior attendants and assistants, and senior and assistant scientists, the additional cost factor is clearly visible. Thus, is it worth the (ideal and financial) effort to establish a mentoring program for medical students?

Recent publications provide us with a clear answer: yes! In 2010, Frei and colleagues investigated and compared 14 mentoring programs for medical students and concluded that 'mentoring is obviously an important career advancement tool which would benefit from early implementation at medical schools'. ${ }^{2}$

Specifically, many of the programs generally aim to monitor and increase student progress in medical studies ${ }^{4}$, $5,39,40$ whereas other programs target specific medical disciplines or subgroups of students. ${ }^{9,41-43}$ The benefits that are reported from the more general mentoring approaches may be classified as follows: increased support and improved networking, ${ }^{3,44}$ professional progress and career development ${ }^{16,36,41,42}$ and increased satisfaction. ${ }^{37,39,45}$

Some of the more specialized mentoring programs target specific medical disciplines, with goals that include increasing interest in emergency or internal medicine $e^{41,42}$, improving experience in humanities ${ }^{15}$ and creating opportunities for research programs or support for research projects. ${ }^{15,16}$ Finally, specific programs for underrepresented medical students resulted in improvements in medical school performance. ${ }^{9}$

Together, both generalized and specific mentoring programs appear to serve as important accompanying interventions for increasing the success and satisfaction of students. However, to the best of our knowledge, no previous examples of integrated or differential mentoring approaches have been published. In a cross-sectional study surveying mentoring programs in Germany published in 2011, there was no description of a similarly differential mentoring program. ${ }^{19}$

The differential mentoring approach has been developed as a synthesis of a cross-sectional survey, expert panels, experience from the pilot trial ${ }^{25}$ and a literature review. ${ }^{2,5,28,38}$ Because the cross-sectional survey respondents rated career-related objectives and psychosocial issues as the most important issues (Figure 1), these data indicate that mentoring serves as a suitable approach to satisfy both types of needs rather than a traditional counseling service. Further results from the cross-sectional survey prompted us to reject a web-based mentoring concept but to focus on individual support by the medical school staff (Table 1). Based on published data ${ }^{5,28,36-38}$ and the initial analyses that are described above, the following objectives for the mentoring program were defined: (i) to establish long-term mentoring for all students and thereby provide individual support for students' overall development; (ii) to foster communication within the medical school; (iii) to increase the success rate for the German Medical Examination, 
specifically during the first part after 2 years of study; and (iv) to establish an early link between teaching and research for the most talented undergraduate students.

The primary results of our pilot trial that was conducted in 2008 indicate an obvious difference between students with strong and less strong study performance concerning preferred topics for advice and counseling. ${ }^{25}$ Furthermore, the students in the low-performing group showed significantly less acceptance of the mentoring program. Thus, the results from the pilot trial and the recommendations from the expert panels that mentoring for all students and mentoring for students with low or high performance should be organized separately encouraged us to establish a differential mentoring program with three parts. These parts are distinguished by their aims, the mentoring model (one-on-one mentoring vs. group mentoring), and the background of mentors.

According to Keyser et al., group mentoring benefits from a larger group dynamic. ${ }^{46}$ Frei et al. proposed the same group size (eight mentees to one mentor) that we had chosen in 2009 for the Basic Mentoring Program for three reasons: to benefit from a group dynamic that results from the contributions of multiple mentees, to reduce anonymity at a large medical school and to increase program availability for all students despite limited resources. ${ }^{2}$ Because lowperforming students hesitated to participate in the mentoring pilot trial compared with high-performing students and because mentors of low-performance groups reported multiple problems that influence performance, we selected one-on-one mentoring for the Mentoring Program PLUS. ${ }^{25}$ For the Mentoring Program for Excellent Students, we made a trade-off (small group mentoring 4:1) with respect to group interaction, availability of mentors and the learning environment that fosters scientific work. Consistent with previous studies, mentors were recruited from various departments of the UMC to ensure that they meet the specific interests of multiple mentees and can provide access to accurate information. ${ }^{12,46}$ Mentees with academic difficulties reported a greater need for psychological topics compared with the participants in the high-performance group. ${ }^{25}$ Thus, the selection criteria for mentors who were engaged in the Mentoring Program PLUS include an area of psychosocial interest or professional expertise in counseling.

According to previous studies, compatibility between mentees and mentors is crucial for successful mentorship. ${ }^{46-48}$ Thus, for differential mentoring, we decided that mentees would choose their mentors based on webbased profiles and that the inaugural events would include speed-mentoring. ${ }^{49}$

Recently, von der Borch et al. reported the development of a large-scale mentoring concept based on a needs analysis. ${ }^{32}$ This analysis encompassed a survey of medical students, focus group analyses, and an analysis of the additional expectations of students entering the program. Although the results from these portions of the needs analysis did not differ greatly from our own results (see the results section), the conclusion and thus the concept of the mentoring program differed. Mentoring in the preclinical phase $\left(1^{\text {st }}\right.$ through $4^{\text {th }}$ semesters) is based on peer mentoring by advanced medical students in the "Society Model" of von der Borch et al..$^{32}$, whereas peer mentoring at the UMC was introduced only in the $1^{\text {st }}$ semester because $1^{\text {st }}$ semester students actively voted for this model. However, after the $1^{\text {st }}$ semester, the UMC mentors were physicians or scientists who were either faculty members or staff. Nevertheless, the greatest difference between the program that was designed by von der Borch et al. and our own program lies in their structure. Whereas von der Borch et al. did not distinguish between student groups with different success levels, our conclusion from the initial surveys and pilot trial indicated a clear distinction regarding the mentoring needs of these different groups. Thus, we designed the Basic Mentoring Program to be available for all students but also designed more specialized programs for students with excellent performance or low performance.

\section{Implementation}

A large number of students pose a challenge for a medical school regarding the feasibility of individual mentoring for all students. ${ }^{32}$ Pickles et al. reported stigmatization, a lack of knowledge regarding counseling service and accessibility as barriers. ${ }^{31}$ We assumed that mentoring would suffer less from stigmatization than traditional student advice and psychological counseling services. Our data showing high publicity (93\% to $98 \%$ ) clearly illustrate that the new mentoring program is well known among students at the UMC. Compared with the study of Pickles et al., who reported that only $55 \%$ of students were aware of the on-site counseling service offered at the University of Edinburgh after repeated advertising, the implementation at the UMC was successful with regard to publicity. Thus, the choice of information channels (the eLearning platform and repeated information events before or after the main biochemistry lectures) that was cited by the participants of a previous needs analysis clearly facilitates successful implementation. Furthermore, the differential mentoring approach was able to attract $51 \%$ of the students in the third year following the launch of the novel mentoring program. These data provide some indirect evidence of low levels of stigmatization regarding mentoring and indicate the prevalence of word-of-mouth recommendation from mentees.

\section{Conclusion}

Several limitations for this study should be considered. First, although the response rates were satisfactory compared with those of other medical education studies, a response bias remains possible. Second, the students who volunteered for telephone interviews were self-selected, and this self-selection could have skewed the results toward a 
greater need for mentoring. Third, the members of expert panels who were invited by the deanery to represent different stakeholders (faculty board, external experts, medical and scientific staff, and students) may not be representative for other faculties. Fourth, the evaluation data from the 2008-2010 mentoring cohort have not been included in this article to avoid information overload.

Despite these limitations, the formal differential mentoring approach that is based on empirical data with favorable response rates and a serious literature review may be of great interest for other medical schools. The formal differential mentoring program allows for social inclusion with equal opportunities, regardless of gender, race and background. ${ }^{1}$ For example, students who do not have the opportunity to gain information from relatives or friends who are employed as physicians can benefit from enhanced networking and communication with staff via mentoring. Moreover, the differential approach enables the effective promotion of diverse talent. High-performing students with an interest in research can be guided to research early in their academic careers, whereas students with difficulties can be identified early, guided through difficulties by a trusted person and referred to professional counselors in situations of serious psychological distress.

In conclusion, mentoring programs serving life-long learning must be specifically tailored to meet the demands of students and faculty. Thus, initial surveys among students and perhaps a pilot trial followed by a serious decision-making process for the faculty to reflect financial resources and long-term aims are prerequisites for the development of a successful mentoring program.

On a wider scale, the implementation of a mentoring program may serve to better support, integrate and motivate students; to support the teaching and learning process; and to enhance both the satisfaction and success of academic training for physicians. We consider differential mentorship to be an important flanking measure of medical school curricula to ensure both equal opportunities and the promotion of diverse talent. This study may assist other medical schools or institutions in adopting differential mentorship and enhancing their efforts to establish formal mentoring programs for students in general.

There is a need for a greater understanding of how mentoring at medical schools influences student satisfaction, their personal and professional development and faculty development in transitioning to an organization with a mentoring culture. Future research should evaluate the mentoring process in detail, including contextual factors, the matching process, value and the potential pitfalls of (differential) mentoring. Furthermore, validated instruments or suitable methods must be developed to compare the short- and long-term value of formal mentoring programs, including the perspectives of all stakeholders (mentees, mentors, and faculty boards). Longitudinal studies that compare medical school histories and profes- sional careers of students in a controlled design with and without mentoring would be of great interest.

\section{Acknowledgements}

The authors wish to thank all of the mentors and mentees whose participation and enthusiasm facilitated this project. This project has been supported by the Claussen-SimonStiftung, Hamburg, Germany (grant no 0678/150). Special gratitude is expressed to Professor Uwe Koch (Dean of Faculty, University Medical Center Hamburg-Eppendorf) for continuous support and critical comments on the manuscript.

\section{Conflict of Interest}

The authors declare that they have no conflict of interest.

\section{References}

1. Clutterbuck D. Everyone needs a mentor. Fostering talent in your organisation. London: chartered institute of personnel and development; 2004.

2. Frei E, Stamm M, Buddeberg-Fischer B. Mentoring programs for medical students--a review of the PubMed literature 2000-2008. BMC Med Educ. 2010;10:32.

3. Macaulay W, Mellman LA, Quest DO, Nichols GL, Haddad J, Jr., Puchner PJ. The advisory dean program: a personalized approach to academic and career advising for medical students. Acad Med. 2007;82(7):718-22.

4. Buddeberg-Fischer B, Herta KD. Formal mentoring programmes for medical students and doctors--a review of the Medline literature. Med Teach. 2006;28(3):248-57.

5. Sambunjak D, Straus SE, Marusic A. Mentoring in academic medicine: a systematic review. JAMA. 2006;296(9):1103-15.

6. Wong EY, Bigby J, Kleinpeter M, Mitchell J, Camacho D, Dan A, et al. Promoting the advancement of minority women faculty in academic medicine: the national centers of excellence in women's health. J Womens Health Gend Based Med. 2001;10(6):541-50.

7. Dutta R, Hawkes SL, Kuipers E, Guest D, Fear NT, Iversen AC. One year outcomes of a mentoring scheme for female academics: a pilot study at the Institute of Psychiatry, King's College London. BMC Med Educ. 2011;11:13. 8. Fried LP, Francomano CA, MacDonald SM, Wagner EM, Stokes EJ, Carbone KM, et al. Career development for women in academic medicine. JAMA. 1996;276(11):898-905.

9. Tekian A, Jalovecky MJ, Hruska L. The impact of mentoring and advising at-risk underrepresented minority students on medical school performance. Acad Med. 2001;76(12):1264.

10. Abernethy AD. A mentoring program for underrepresented-minority students at the University of Rochester School of Medicine. Acad Med. 1999;74(4):356-9.

11. Johnson JC, Williams B, Jayadevappa R. Mentoring program for minority faculty at the University of Pennsylvania School of Medicine. Acad Med. 1999;74(4):376-9.

12. Lewellen-Williams C, Johnson VA, Deloney LA, Thomas BR, Goyol A, Henry-Tillman R. The POD: a new model for mentoring underrepresented minority faculty. Acad Med. 2006;81(3):275-9.

13. Dekker H, Driessen E, Ter Braak E, Scheele F, Slaets J, Van Der Molen T, et al. Mentoring portfolio use in undergraduate and postgraduate medical education. Med Teach. 2009;31(10):903-9.

14. Driessen E, van Tartwijk J, Vermunt JD, van der Vleuten CP. Use of portfolios in early undergraduate medical training. Med Teach. 2003;25(1):18-23.

15. Kanter SL, Wimmers PF, Levine AS. In-depth learning: one school's initiatives to foster integration of ethics, values, and the human dimensions of medicine. Acad Med. 2007;82(4):405-9.

16. Zier K, Friedman E, Smith L. Supportive programs increase medical students' research interest and productivity. J Investig Med. 2006;54(4):2017 . 
17. Driessen EW, Overeem K, van der Vleuten CP. Get yourself a mentor. Med Educ. 2011;45(5):438-9.

18. Stamm M, Buddeberg-Fischer B. The impact of mentoring during postgraduate training on doctors' career success. Med Educ. 2011;45(5):48896.

19. Meinel FG, Dimitriadis K, von der Borch P, Stormann S, Niedermaier S, Fischer MR. More mentoring needed? A cross-sectional study of mentoring programs for medical students in Germany. BMC Med Educ. 2011;11.

20. Dahlin M, Joneborg N, Runeson B. Stress and depression among medical students: a cross-sectional study. Med Educ. 2005;39(6):594-604.

21. Moffat KJ, McConnachie A, Ross S, Morrison JM. First year medical student stress and coping in a problem-based learning medical curriculum. Med Educ. 2004;38(5):482-91.

22. Dyrbye LN, Thomas MR, Shanafelt TD. Systematic review of depression, anxiety, and other indicators of psychological distress among U.S. and Canadian medical students. Acad Med. 2006;81(4):354-73.

23. Jeong Y, Kim JY, Ryu JS, Lee KE, Ha EH, Park H. The associations between social support, health-related behaviors, socioeconomic status and depression in medical students. Epidemiol Health. 2010;32:e2010009.

24. Chenot JF. Undergraduate medical education in Germany. Ger Med Sci. 2009;7:Doc02.

25. Petersen-Ewert C, Kurré J, Scholl J, Guse AH, Bullinger M. Einführung eines mentorenprogramms für den ersten abschnitt des studiums der humanmedizin: ergebnisse eines pilotprojektes. GMS Z Med Ausbild. 2009;26(3):Doc32.

26. Stratton TD, Rudy DW, Sauer MJ, Perman JA, Jennings CD. Lessons from industry: one school's transformation toward "lean" curricular governance. Acad Med. 2007;82(4):331-40

27. Campbell M, Fitzpatrick R, Haines A, Kinmonth AL, Sandercock P, Spiegelhalter D, et al. Framework for design and evaluation of complex interventions to improve health. BMJ. 2000;321(7262):694-6.

28. Malik S. Students, tutors and relationships: the ingredients of a successful student support scheme. Med Educ. 2000;34(8):635-41.

29. Isserstedt W, Middendorff E, Kandulla M, L. B, Leszczensky M. Die wirtschaftliche und soziale lage der studierenden in der bundesrepublik deutschland 2009. Ergebnisse der 19. Sozialerhebung des deutschen studentenwerks (DSW). Durchgeführt durch HIS hochschul-informationssystem. 2010 [cited 18 June 2012]. Avaialble from: http://www.sozialerhebung.de/download/19/Soz19_Haupt_Internet_A5.pdf : Bundesministerium für Bildung und Forschung (BMBF).

30. Ey SH, Kris R; Shaw, Darlene L. Attitudes and factors related to seeking mental health treatment among medical and dental students. Journal of College Student Psychotherapy. 2000;14(3):23-39.

31. Pickles KJ, Rhind SM, Miller R, Jackson S, Allister R, Philp J, et al. Potential barriers to veterinary student access to counselling and other support systems: perceptions of staff and students at a UK veterinary school. Vet Rec. 2012;170(5):124

32. von der Borch P, Dimitriadis K, Stormann S, Meinel FG, Moder S, Reincke $\mathrm{M}$, et al. A novel large-scale mentoring program for medical students based on a quantitative and qualitative needs analysis. GMS Z Med
Ausbild. 2011;28(2):Doc26.

33. Hsieh HF, Shannon SE. Three approaches to qualitative content analysis. Qual Health Res. 2005;15(9):1277-88.

34. Mayring P. Qualitative inhaltsanalyse : grundlagen und techniken. Weinheim: Beltz; 2007.

35. Woessner R, Honold M, Stehle I, Stehr S, Steudel WI. Faculty mentoring programme--ways of reducing anonymity. Med Educ. 1998;32(4):441-3.

36. Kalet A, Krackov S, Rey M. Mentoring for a new era. Acad Med. 2002;77(11):1171-2.

37. Aagaard EM, Hauer KE. A cross-sectional descriptive study of mentoring relationships formed by medical students. J Gen Intern Med. 2003;18(4):298-302.

38. Cottrell DJ, McCrorie P, Perrin F. The personal tutor system: an evaluation. Med Educ. 1994;28(6):544-9.

39. Coates WC, Crooks K, Slavin SJ, Guiton G, Wilkerson L. Medical schoo curricular reform: fourth-year colleges improve access to career mentoring and overall satisfaction. Acad Med. 2008;83(8):754-60.

40. Goldstein EA, Maclaren CF, Smith S, Mengert TJ, Maestas RR, Foy HM, et al. Promoting fundamental clinical skills: a competency-based college approach at the University of Washington. Acad Med. 2005;80(5):423-33.

41. Coates WC, Ankel F, Birnbaum A, Kosiak D, Broderick KB, Thomas S, et al. The virtual advisor program: linking students to mentors via the world wide web. Academic Emergency Medicine. 2004;11(3):253-5.

42. Dorrance KA, Denton GD, Proemba J, La Rochelle J, Nasir J, Argyros G, et al. An internal medicine interest group research program can improve scholarly productivity of medical students and foster mentoring relationships with internists. Teach Learn Med. 2008;20(2):163-7.

43. Kosoko-Lasaki O, Sonnino RE, Voytko ML. Mentoring for women and underrepresented minority faculty and students: experience at two institutions of higher education. J Natl Med Assoc. 2006;98(9):1449-59.

44. Scheckler WE, Tuffli G, Schalch D, MacKinney A, Ehrlich E. The class mentor program at the University of Wisconsin Medical School: a unique and valuable asset for students and faculty. WMJ. 2004;103(7):46-50.

45. Zink BJ, Hammond MM, Middleton E, Moroney D, Schigelone A. A comprehensive medical student career development program improves medical student satisfaction with career planning. Teach Learn Med. 2007;19(1):55-60.

46. Keyser DJ, Lakoski JM, Lara-Cinisomo S, Schultz DJ, Williams VL, Zellers DF, et al. Advancing institutional efforts to support research mentorship: a conceptual framework and self-assessment tool. Acad Med. 2008;83(3):217-25.

47. Jackson VA, Palepu A, Szalacha L, Caswell C, Carr PL, Inui T. "Having the right chemistry": a qualitative study of mentoring in academic medicine. Acad Med. 2003;78(3):328-34.

48. Thorndyke LE, Gusic ME, Milner RJ. Functional mentoring: a practical approach with multilevel outcomes. J Contin Educ Health Prof. 2008;28(3):157-64.

49. Cook DA, Bahn RS, Menaker R. Speed mentoring: an innovative method to facilitate mentoring relationships. Med Teach. 2010;32(8):692-4. 